URL: http://ojs.unimal.ac.id/index.php/ekonomi_regional

\title{
Pengaruh Jumlah Uang Beredar (JUB) dan Ekspor Tembakau Terhadap Kurs di Indonesia
}

\author{
${ }^{* a}$ Siti Aryani, ${ }^{* b}$ Murtala \\ * Fakultas Ekonomi dan Bisnis Universitas Malikussaleh \\ a Corresponding author:sitiaryani678@gmail.com \\ b tala.murtala@gmail.com
}

\begin{tabular}{l} 
A R T I C L E I N O RM A T I O \\
\hline Keywords: \\
Money Supply, Tobacco Export \\
Exchange Rate.
\end{tabular}

A B S T R A C T

This study aims to determine the effect of the money supply and export of tobacco on the exchange rate in Indonesia. This study uses time series data from 1986 to 2016. The study, this uses Multiple linear regression and Vector Autoregression Model (VAR). Based on the results of the study obtained, it can be seen that partially the money supply had a positive and significant effect on the exchange rate and the export of tobacco had a negative and significant effect on the exchange rate. While simultaneously, the money supply and exports of tobacco had a positive and significant effect on the exchange rate in Indonesia. Furthermore, the results of the VAR analysis model showed that the exchange rate why influenced significantly and positively by the movement itself. The money supply had a positive and insignificant effect on the exchange rate while tobacco exports had a positive and significant effect on the exchange rate.

\section{PENDAHULUAN}

Nilai tukar merupakan aspek yang sangat penting untuk mendukung terwujudnya transaksi perdagangan dari satu negara dengan negara lain. Dengan adanya sistem nilai tukar ini, mata uang yang berbeda-beda pada setiap negara dapat digunakan di seluruh dunia dengan syarat-syarat yang telah dibuat dan disepakati bersama. Ketidak stabilan kurs rupiah yang terjadi ini membuat pergerakan perubahan nilai rupiah sangat rentan bagi para pelaku ekonomi. Perkembangan Nilai tukar dari tahun 2007 - 2016 adalah sebagai berikut:

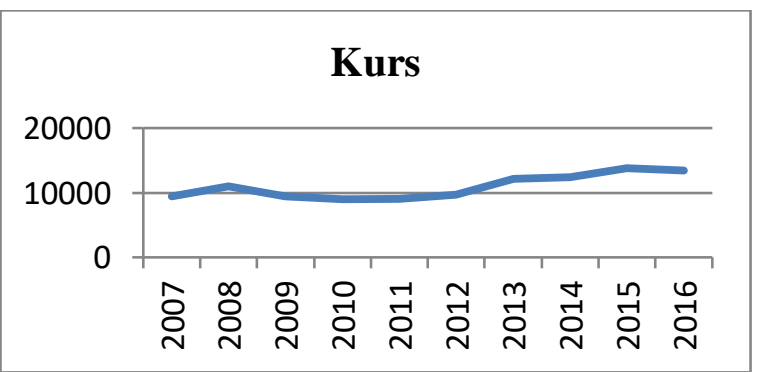

Sumber: Kementrian Perdagangan, 2019.

Gambar 1

Perkembangan Nilai Tukar di Indonesia Tahun 2007-2016
Berdasarkan Gambar 1 di atas memperlihatkan perkembangan nilai tukar di Indonesia dari tahun 2007-2016. Nilai tukar dari tahun 2007-2016 terus mengalami fluktuasi, dimana nilai tukar pada tahun 2014-2015 terdepresiasi dari Rp.12.440 menjadi Rp.13.795 melemah mencapai 0,15\%.Penguatan dollar AS terhadap nilai tukar rupiah disebabkan oleh adanya inflasi didalam negeri yang cukup tinggi yang memicu laju nilai tukar rupiah kembali melemah. Berikut perkembangan jumlah uang beredar di Indonesia dari tahun 2007-2016 dapat dilihat dalam Gambar 2:

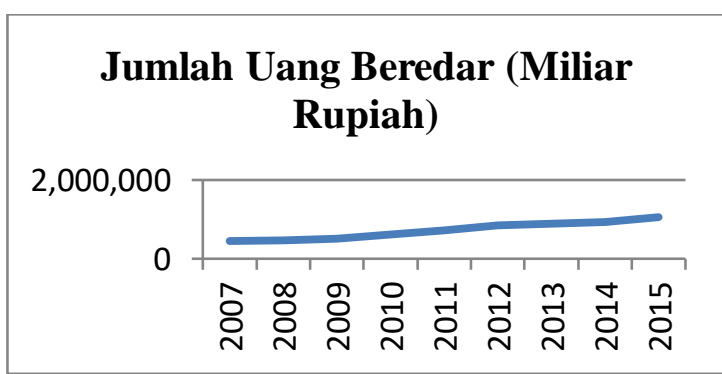

Sumber: Statistik Keuangan Indonesia, 2019.

Gambar 2

Perkembangan Jumlah Uang Beredar di Indonesia Tahun 2007-2016 
Perkembangan jumlah uang beredar tahun 2007-2016 terus mengalami peningkatan. Menurut Ardiyanto \& Ma'aruh, (2014). Penambahan uang beredar akan membuat melemahnya nilai tukar atau terdepresiasi. Pada tahun 2009, 2010 dan 2016 jumlah uang beredar meningkat sedangkan nilai tukar rupiah melemah secara teori hal ini tidak sesuai, dimana jumlah uang beredar pada tahun 2009 sebesar Rp.515.824 miliar tetapi nilai tukar rupiah terapresiasi sebesar Rp.9.400, begitu juga pada tahun 2010 jumlah uang beredar juga semakin meningkat sebesar Rp.605.411 Milyar tetapi nilai tukar rupiah terapresiasi sebesar Rp. 8.991.

Keterkaitan jumlah uang beredar dan kurs tergantung pada penawaran atas uang tersebut, jika penawaran atas rupiah meningkat maka nilai mata uang akan melemah, sedangkan jika penawaran atas rupiah menurun maka nilai mata uang rupiah akan menguat. Peningkatan jumlah uang beredar ini di sebabkan oleh inflasi dan upaya Bank Indonesia melakukan intervensi pasar (aktifitas perbankkan). Jika Bank Indonesia menambah valas ke pasar maka jumlah uang beredar akan meningkat disisi lain kebutuhan masyarakatmeningkat. Hal ini tentu akan meningkatkan permintaan barang dan jasa. Peningkatan tersebut pada gilirannya akan meningkatkan permintaan uang.

Pada tahun 1990-an Indonesia mulai menjadi negara produsen tembakau dunia, yang berada di posisi 8 besar negara produsen tembakau di dunia. Sampai dengan saat ini Indonesia masih terus meningkatkan produksi tembakau. Berikut ini perkembangan nilai ekspor tembakau dari tahun 2007-2016 yaitu:

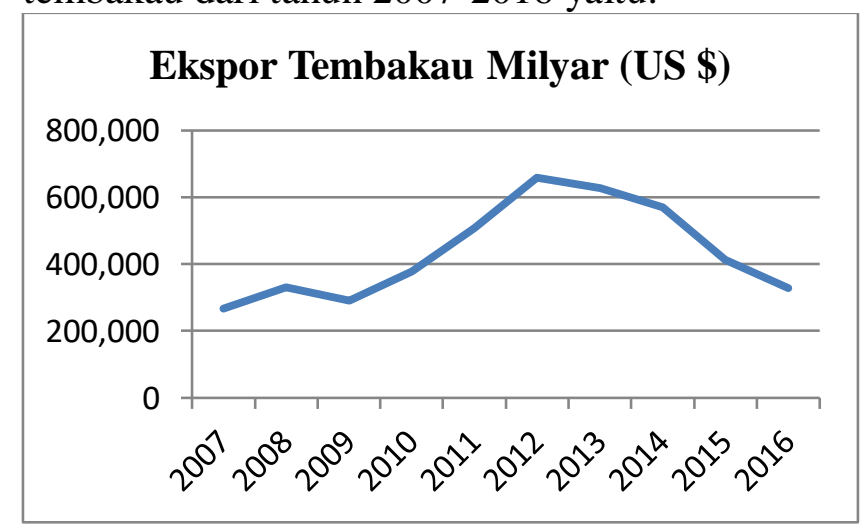

Sumber: Badan Pusat Statistik (BPS), 2019.

Gambar 3

\section{Perkembangan Ekspor Tembakau di Indonesia Tahun 2007-2016}

Berdasarkan Gambar 3 di atas tingkat ekspor tembakau mengalami fluktuasi sejak tahun 2007-2016. Pada tahun 2010-2012 ekspor tembakau terus mengalami peningkatan dari 378.710 miliar US \$ terus meningkat mencapai 658.922 miliar US \$. Secara teori menurut Sanusi, (2004) apabila suatu negara tinggi nilai ekspornya maka akan mengakibatkan semakin tinggi juga permintaan rupiah yang kemudian rupiah menjadi menguat terhadap dollar. Meningkatnya ekspor akan berdampak pada menguatnya mata uang dalam jangka panjang. Tetapi, justru ini berbading terbalik dengan teori dimana pada tahun 2012 ekspor meningkat sebesar 658.922 miliar US\$ sedangkan nilai tukar terdepresiasi sebesar Rp. 9.670, begitu pula pada tahun 2016 ekspor tembakau menurun sebesar 328.585 miliar US\$, nilai tukar rupiah menguat/apresiasi yaitu sebesar 13.436 .

Melemahnya nilai tukar rupiah ini diikuti dengan melemahnya pertumbuhan ekonomi indonesia yang tidak lepas dari fenomena ekonomi global dan devaluasi mata uang yuan. Berdasarkan penelitian sebelumnya yang berkaitan dengan pengaruh kurs telah diteliti oleh(Bau et al., 2016), dan (Sedyaningrum et al., 2016) yang memberikan fokus pada inflasi, ekspor dan impor. Selanjutnya penelitian yang memberikan fokus pada suku bunga, jumlah uang beredar, dan Produk Domestik Bruto yang diteliti oleh (Noor, 2011), (Hakim et al., 2013) dan (Ulfa, 2012).Penelitian ini menitik beratkan pada ekspor tembakau secara khusus untuk melihat keterkaitannya dengan kurs yang masih jarang dipublikasi.

Tujuan penelitian ini adalah untuk mengetahui seberapa besar pengaruh jumlah uang beredar dan ekspor tembakau terhadap kurs di Indonesia. Selanjutnya bagian kedua penelitian ini membahas tinjauan teoritis dari variabel-variabel terkait, pembatasan kajian dan teknik analisis yang dipaparkan dibagian tiga untuk melihat hasil dan analisis dengan dilihat dari pengaruh dan hubungan dari penelitian ini.

\section{TINJAUAN TEORITIS Nilai Tukar Rupiah (Kurs)}

Menurut Purnomo et al., (2013) kurs mata uang adalah harga mata uang dari suatu negara yang diukur, dibandingkan, dan dinyatakan dalam nilai mata uang negara lainnya.

Menurut Bau et al., (2016) teori nilai tukar yaitu, Teori IRP (Interest Rate Parity) teori ini menganalisa tentang hubungan antara kurs valas dengan tingkat suku bunga. Teori ini juga menyatakan bahwa perbedaan tingkat bunga pada 
pasar uang internasional akan cenderung sama dengan forward rate atau discount.

\section{Jumlah Uang Beredar}

Menurut Boediono (2000), jumlah uang beredara dalam arti sempit (M1) merupakan uang dalam bentuk uang giral dan uang kartal yang dipegang dan digunakan oleh masyarakat sebagai alat transaksi pembayaran sehari-hari.

Hubungan jumlah uang beredar dengan nilai tukar adalah dimana jumlah uang beredar tergantung kepada penawaran uang tersebut, jika penawaran atas rupiah meningkat maka nilainya akan terdepresiasi (melemah), sedangkan jika penawaran atas rupiah menurun maka nilai mata uang rupiah akan terapresiasi (menguat), maka hubungan jumlah uang beredar terhadap kurs berpenagruh negatif (Muchlas 2015).

Jika dibandingkan penelitian penulis dengan penelitian sebelumnya maka terdapat perbedaan dan persamaan yaitu sebagai berikut Ali et al., (2015) judul penelitian ini adalah Impact of Interest Rate, Inflation and Money Supply on Exchange Rate Volatility in Pakistan. Penelitian ini menggunakan model analisis Johansen Cointegrasion dan Vector Error Correction Model (VECM).Hasil penelitiannya yaitu bahwa terdapat hubungan jangka pendek dan jangka panjang antara inflasi dan volatilitas nilai tukar.Pasokan uang yang tinggi dan kenaikan suku bunga meningkatkan tingkat harga (inflasi) yang mengarah pada peningkatan volatilitas nilai tukar.

\section{Ekspor Tembakau}

Ekspor adalah proses perpindahan barang atau komoditas dari suatu negara ke negara lain secara legal, umumnya dalam proses perdagangan internasional (Wardhana, 2011). Barang ekspor adalah keunggulan ekonomi dari sebuah negara. Keunggulan tersebut itu yang akan menjadi pemicu bagi pertumbuhan ekonomi negara pengekspor. Ekspor menyebabkan suatu Negara mendapat mata uang asing. Ekspor yang lebih besar dari pada impor akan menyebabkan surplus dalam neraca perdagangan dan membantu mengurangi defisit dalam transaksi berjalan.

Ekspor adalah penjualan barang yang dilakukan dari suatu negara ke negara lain yang tidak dapat memproduksi atau menghasilkan barang tersebut dengan tujuan untuk meraut keuntungan baik untuk individual, perusahaan, bahkan untuk negara.

Hubungan ekspor tembakau dengan kurs menurut Permatasari (2017) yaitu, semakin tinggi eskpor akan mengakibatkan semakin tingginya permintaan terhadap rupiah sehingga nilai tukar rupiah akan menguat/apresiasi. Begitupula sebaliknya apabila ekspor tembakau menurun maka nilai tukar rupiah akan melemah/depresiasi, maka ekspor tembakau memiliki hubungan yang positif terhadap Kurs.

Mabeta et al., (2015) judul penelitian ini adalah Growth of Tobacco Exports in Zambia : An ARDL Approach. Model penelitian ini menggunkan model analisis Auto Regresive Distributed Lag (ARDL).Hasil penelitiannya yaitu bahwa ekpor tembakau secara signifikan dipengaruhi oleh nilai tukar efektif nyata, pendapatan rill mitra dagang dan investasi asing langsung dalam jangka pendek, sementara hanya nilai tukar efektif nyata dan pendapatan rill mitra dagang yang mempengaruhi pertumbuhan ekspor tembakau dalam jangka panjang.

\section{Kerangka Konsptual}

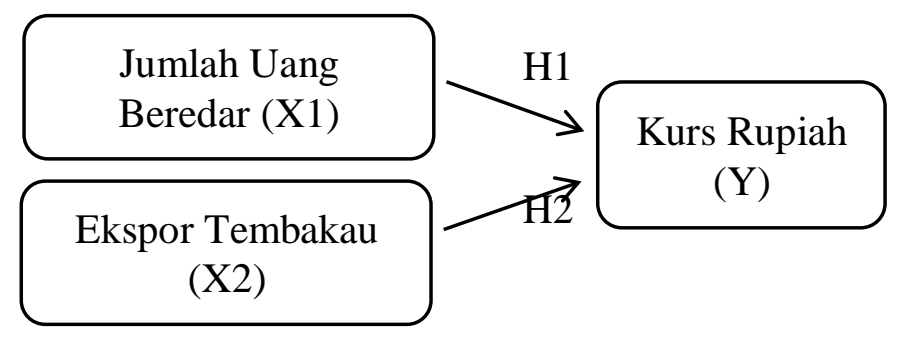

\section{Gambar 4 Kerangka Konseptual}

Berdasarkan kerangka konseptual dalam penelitian ini menggunakan variabel independen jumlah uang beredar (JUB) sebagai X1, dan Ekspor Tembakau sebagai X2 berpengaruh terhadap nilai tukar (kurs) sebagai variabel dependent (Y).

\section{Hipotesis}

Dalam penelitian ini penulis mengajukan hipotesis guna untuk memberikan arahan serta pedoman dalam melakukan peneliatian. Adapun hipotesis yang digunakan didalam penelitian ini adalah sebagai berikut:

H1 :Diduga jumlah uang beredar berpengaruh negatif dan signifikan terhadap kurs di Indonesia.

H2 : Diduga ekspor tembakau berpengaruh positif dan signifikan terhadap kurs di Indonesia 


\section{METODE PENELITIAN}

Data dan sumber Data

Yang menjadi objek dalam penelitian ini adalah jumlah uang beredar, ekspor tembakau dan kurs di Indonesia.data yang digunakan adalah data time series dalam kurun waktu 31 tahun yaitu dari tahun 1986-2016.

\section{Operasional Variabel}

Dalam melakukan penelitian diperlukan menentukan karakter yang akan diteliti yang biasanya dikenal dengan variabel. Variabel merupakan gambaran nyata mengenai fenomenafenomena penelitian. Operasional variabel adalah petunjuk tentang bagaimana cara mengukur suatu variabel dalam penelitian. Dalam penelitian ini terdapat dua variabel yaitu terikat (Dependen) dan variabel bebas (Independen).Masing-masing definisi operasional variabel bebas dalam penelitian ini adalah sebagai berikut ini:

1. Kurs (Y) rupiah/dollar AS merupakan banyaknya rupiah yang diperlukan untuk memperolehsatu unit mata uang asing yaitu dollar AS.

2. Jumlah Uang Beredar (X1) adalah uang kartal yang terdiri dari uang logam dan uang kertas yang ada dalam peredaran, uang giral dan uang kuasi.

3. Ekspor Tembakau (X2) dalah suatu kegiatan menjual atau mengeluarkan barang dari dalam negeri keluar negeri.

\section{Metode Analisis Data}

\section{Model Linear Ordinary Least Square (OLS)}

Untuk mengetahui pengaruh jumlah uang beredar dan ekspor tembakau terhadap kurs di Indonesia maka, metode yang digunakan dalam penelitian ini adalah uji regresi linear berganda baik secara simultan maupun parsial. Adapun rumus regresi linear berganda adalah sebagai berikut:

\section{Dimana:}

$$
Y_{t}=\beta_{0}+b_{1} \operatorname{Ln} X_{1} \mathrm{t}+b_{2} \operatorname{Ln} X_{2} \mathrm{t}+\mathrm{et}
$$

$\begin{array}{cl}Y_{t} & : \text { Nilai tukar } \\ \beta_{0} & : \text { Konstanta } \\ X_{1} & : \text { Jumlah uang beredar } \\ X_{2} & : \text { Ekspor tembakau } \\ \beta_{1}-\beta_{2} & : \text { Koefisien regresi masing-masing } \\ & \text { variabel independen } \\ \mathrm{e} & : \text { error term }\end{array}$

$t \quad$ : Periode waktu

Tahapan pengujian OLS adalah sebagai berikut:

\section{Uji Normalitas}

Uji normalitas adalah untuk melihat apakah data berdistribusi secara normal atau tidak.Pengujian normalitas dapat dilakukan dengan menggunakan metode Jarque-Bera (J-B) (Widarjono, 2013). Jika nilai probability dari statistik J-B lebih besar dari taraf kepercayaan $1 \%$ $(0,01)$ berarti bahwa residual data berdistribusi normal. Sebaliknya jika nilai probability dari statistik J-B lebih kecil dari taraf kepercayaan $1 \%$ $(0,01)$.

\section{Uji Asumsi Klasik}

Menurut Gujarati, (2004) uji asumsi klasik adalah sebagai berikut:

\section{Uji Multikolineritas}

Uji multikolinearitas adalah hubungan linear yang terjadi diantara variabel independen.Multikolinearitas dalam penelitian ini diuji dengan melihat nilai tolerance dan variance inflation factor (VIF). Apabila nilai VIF < 10 maka diduga tidak ada multikolinearitas. Begitupula nilai tolerance yang mendekati satu maka bisa disimpulkan juga tidak ada masalah multikolinearitas (Gujarati, 2003).

\section{Uji Autokorelasi}

Menurut Firdaus (2004), autokorelasi adalah gangguan pada fungsi regresi yang berupa korelasi diantara faktor gangguan. Ada tidaknya autokorelasi juga dapat dilihat dari nilai probabilitas Chi-Square $\left(x^{2}\right)$. Jika nilai probabilitas lebih besar dari nilai $\alpha$ yang dipilih maka kita menerima $H_{0}$ yang berarti tidak ada autokorelasi. Sebaliknya jika nilai probabilitas lebih kecil dari nilai $\alpha$ yang dipilih maka kita menolak $H_{0}$ yang berarti ada masalah autokorelasi(Widarjono, 2017).

\section{Uji Heteroskedastisitas}

Uji Heteroskedastisitas bertujuan menguji apakah dalam model regresi terjadi ketidaksamaan variance dari residual satu pengamatan ke pengamatan yang lain (Ghozali, 2007).Metode pengujian yang lain dapat digunakan adalah metode White dimana hipotesis Heteroskedastisitas yang dipakai: 
Ho: tidak ada heteroskedastisitas $(>0,05)$

Ha: ada heteroskedastisitas $(<0,05)$

\section{Pengujian Statistik}

\section{Uji Statistik t (Uji Parsial)}

Uji t dilakukan untuk melihat signifikansi dari pengaruh variabel bebas secara individual terhadap variabel terikat dengan menganggap variabel bebas lainnya adalah konstan (Gujarati, 2003). Adapun kriteria pengujiannya adalah sebagai berikut:

a. Jika t hitung > t tabel maka menerima Ha yang artinya variabel bebas (X) secara parsial mempengaruhi variabel terikat (Y).

b. Jika t hitung $<\mathrm{t}$ tabel maka menolak Ha yang artinya variabel bebas (X) secara parsial tidak mempengaruhi variabel terikat (Y).

\section{Uji Statistik f (Uji Simultan)}

Uji F dilakukan untuk mengetahui apakah variabel independen secara keseluruhan signifikan secara statistik dalam mempengaruhi variabel dependen. Apabila uji $\mathrm{F}>\mathrm{F}$ tabel maka variabel independen secara keseluruhan berpengaruh terhadap variabel dependen (Gujarati, 2003). Adapun kriteria pengujian yang digunakan sebagai berikut:

a. Jika $\mathrm{F}$ hitung $>\mathrm{F}$ tabel maka menerima Ha yang artinya variabel bebas $(\mathrm{X})$ secara simultan atau serentak berpengaruh signifikan variabel terikat (Y).

b. Jika $\mathrm{F}$ hitung $<\mathrm{F}$ tabel maka menolak Ha yang artinya variabel bebas (X) secara simultan atau serentak tidak berpengaruh signifikan variabel terikat (Y).

\section{Koefisien Determinasi}

Koefisien determinasi $\left(R^{2}\right)$ pada intinya mengukur seberapa jauh kemampuan model dalam menerangkan variasi variabel terikat.Nilai koefisien determinasi adalah antara nol dan satu $\left(0<R^{2}<1\right)$.Nilai $R^{2}$ yang terkecil berarti kemampuan variabel-variabel independen dalam menjelaskan variasi variabel terikat amat terbatas.Nilai yang mendekati satu berarti variabel-variabel bebas memberikan hampir semua informasi yang dibutuhkan untuk memprediksi variasi variabel terikat (Gujarati, 2006).

\section{Koefisien Korelasi}

Menurut Sugiono (2013) r adalah koefisien korelasi yang mengukur tingkat hubungan antara variabel dependen ( $\mathrm{Y}$ ) dengan semua variabel independen yang menjelaskan secara bersama-sama dan nilainya selalu positif.

\section{Model Vactor Autogeression (VAR) \\ Model Vactor Autogeression (VAR) merupakan salah satu metode time series yang digunakan dalam penelitian, terutama dalam bidang ekonomi. Model VAR adalah model linier sehingga kita tidak perlu khawatir tentang bentuk model serta model VAR mudah diestimasi dengan menggunakan metode OLS (Widarjono, 2017).}

Adapun persamaan VAR secara umum adalah sebagai berikut:

$$
\begin{aligned}
& K U R S_{t}=\alpha+\sum_{i=1} \beta_{1} K U R s_{t-i}+ \\
& \sum_{i=1} \beta_{2} J U B_{t-i}+\sum_{i=1} \beta_{3} E K S_{t-i}+\varepsilon_{t 1}
\end{aligned}
$$

\section{Keterangan :}

$\begin{array}{ll}\text { KURS } & \text { : Nilai Tukar } \\ \text { JUB } & \text { : Jumlah Uang Beredar } \\ \text { EKS } & : \text { Ekspor Tembakau } \\ \varepsilon_{t 1} & : \text { Faktor Gangguan } \\ \beta_{1} & : \text { Konstantan }\end{array}$

Tahapan Uji Model VAR adalah sebagai berikut:

\section{Uji Stasioneritas}

Pengujian stasioneritas ini dilakukan dengan menguji akar-akar unit untuk menguji apakah data runtut waktu tersebut stasioner atau tidak (Prawoto \& Basuki, 2016).

\section{Penentuan Lag Optimal}

Pemeriksaan lag digunakan untuk menentukan panjang lag optimal yang akan digunakan dalam analisis selanjutnya dan akan menentukan estimasi parameter untuk model VAR (Widarjono,2017).

\section{Uji Kausalitas Granger}

Pengambilan keputusan dalam uji kausalitas dapat dilakukan dengan membandingkan nilai tstatistik hasil estimasi dengan nilai t-tabel atau 
dengan melihat nilai probabilitas F-statistik. Jika nilai t-statistik hasil estimasi lebih besar dari nilai t-tabel atau nilai probabitas F-statistik $<\dot{\alpha}=5 \%$, maka H0 di tolak artinya terdapat pengaruh antara dua variabel yang diuji, dan begitu juga sebaliknya.

\section{Uji Implus Response}

IRF menunjukkan bagaimana respon dari setiap variabel endogen sepanjang waktu terhadap kejutan dari variabel itu sendiri dan variabel endogen lainnya.

\section{Uji Forecast Error Variance \\ Decomposition(FEVD)}

Uji ini dilakukan untuk memberi informasi mengenai bagaimana hubunngan dinamis antara variabel yang dianalisis. Selain itu, FEVD ini dilakukan untuk melihat seberapa besar pengaruh acak guncangan (random shock) dari variabel tertentu terhadap variabel endogen.

\section{HASIL PENELITIAN DAN PEMBAHASAN}

\section{Perkembangan Nilai Kurs Rupiah/Dollar AS}

Kurs dapat diartikan sebagai jumlah mata uang yang harus dibayar untuk mendapatkan satu jenis mata uang asing yang dapat digunakan sebagai alat pembayaran internasional. Kurs berfungsi untuk memudahkan transaksi perdagangan internasional.Setiap perdagangan internasional pasti menggunakan uang untuk alat transaksinya. Berdasarkan data yang diperoleh, maka pergerakan kurs rupiah/dollar AS dari tahun1986-2016 dapat dilihat pada Gambar 5 berikut ini:

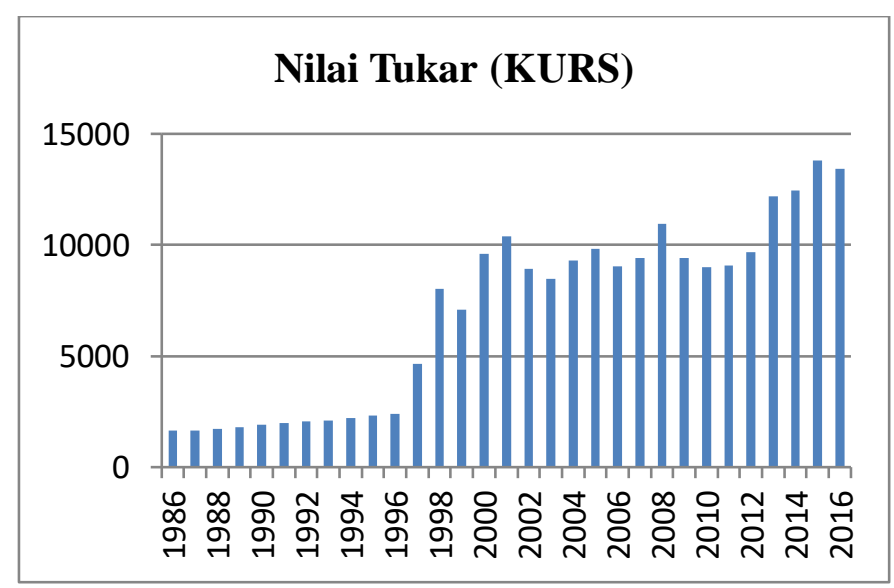

Sumber: Kementrian Perdagangan, 2019.

\section{Gambar 5}

Perkembangan Nilai Tukar Rupiah/Dollar AS
Berdasarkan Gambar 5 memperlihatkan bahwa nilai tukar rupiah mengalami fluktuasi dari tahun 1986-2016.Dari tahun 1986-1998 nilai tukar terus melemah terhadap dollar AS.Melemahnya nilai tukar ini disebabkan oleh harga minya dunia pada tahun 1986.Namun pada tahun 2005 rupiah mengalami pelemahan yaitu sebesar Rp. 9.830 penyebab melemahnya nilai tukar disebabkan oleh adanya spekulasi glogal kenaikan bunga dollar AS dan inflasi dalam negeri yang cukup tinggi yaitu sebesar 7\%-18\%. Dan pada tahun 2008 terjadi krisis keuangan global yang disebabkan oleh krisis Mortgage Subprime Amerika Serikat dan kenaikan harga minyak dunia yang membuat rupiah mengalami trend depresiasi.

Sedangkan pada tahun 2015 rupiah melemah yaitu sebesar Rp. 13.795 angka ini sangat fantastis seiring dengan melemahnya pertumbuhan ekonomi Indonesia yang tak terlepas dari perekonomian global. Melemahnya nilai tuka rupiah ini disebabkan oleh krisis berkepanjangan yang terjadi di yunani, pemulihan ekonomi Amerika Serikat, penghentian quantitative easing di AS dan yang terakhir disebabkan oleh dinamika politik di masa transisi pemerintah.

\section{Perkembangan Jumlah Uang Beredar}

Berikut ini pergerakan jumlah uang beredar dari tahun 1986-2016 dapat dilihat pada Gambar 6.

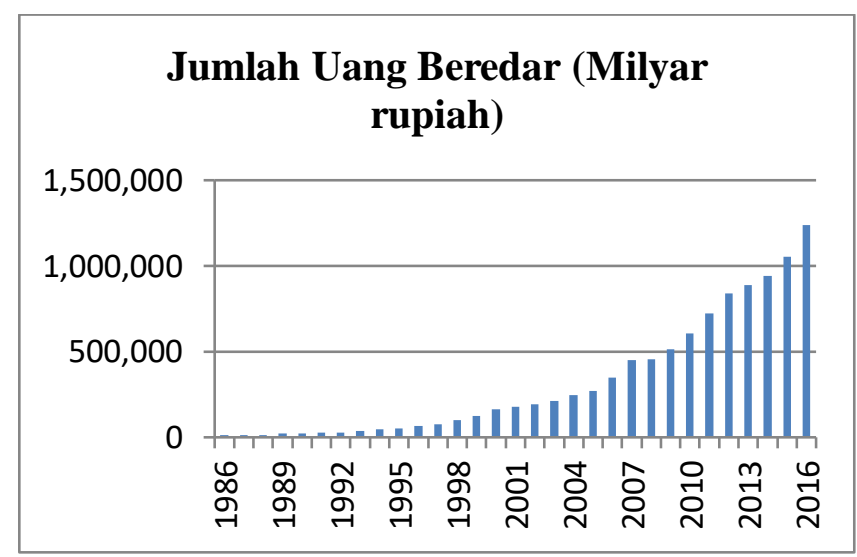

Sumber: Statistik Keuangan Indonesia, 2019.

\section{Gambar 6}

Perkembangan Jumlah Uang Beredar

Berdasarkan Gambar 6 perkembangan nilai tukar dari tahun 1986-2016 terus mengalami peningkatan yang signifikan setiap tahunnya.Semakin banyak jumlah uang beredar dimasyarakat maka nilai tukar rupiah cenderung melemah dan harga-harga meningkat. Tingginya jumlah uang beredar juga menjadi penyebab inflasi yang meninkat sejak 10 tahun terkahir yaitu dari 
tahun 2007-2016 sebesar 5,86\% yang ikut meningkat. Apabila jumlah uang beredar meningkat maka secara bersamaan akan meningkatkan atau menaikkan permintaan yang pada akhirnya jika tidak dibarengi oleh pertumbuhan sektor rill akan menyebabkan naiknya harga.

\section{Perkembangan Ekspor Tembakau}

Pada umumnya temabaku ini digunakan untuk di konsumsi, sebagai bahan pestisida, nikotin tartrat, obat, dan yang sering kali kita lihat dan banyak masyarat gunakan baik dalam negeri maupun luar negeri tembakau digunakan sebagai bahan baku pembuatan rokok.

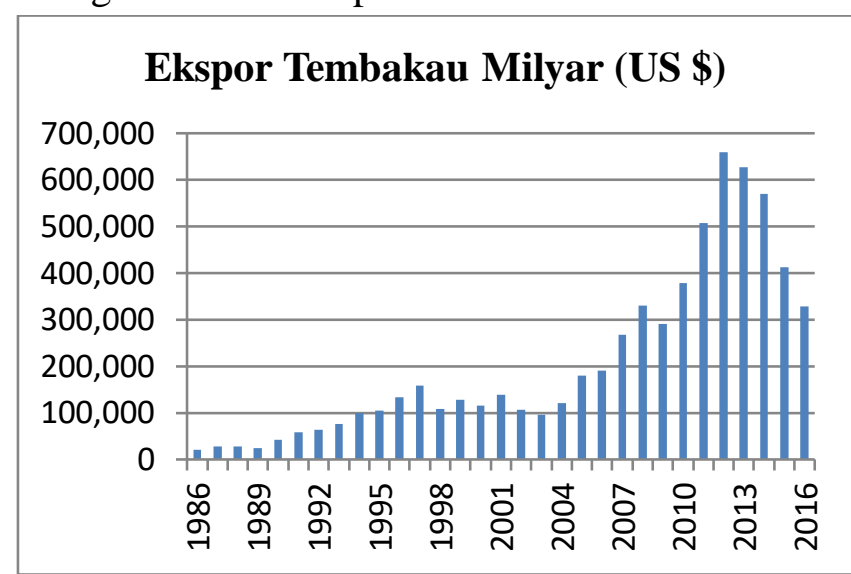

Sumber: Badan Pusat Statistik (BPS), 2019.

\section{Gambar 7}

\section{Perkembangan Ekspor Tembakau}

Berdasarkan Gambar 7 selama tahun 1986-2016 memperlihatkan tingkat ekspor yang berfluktuasi. Dapat dilihat pada tahun 1986 sampai dengan tahun 1996 ekspor tembakau Indonesia relatif meningkat yang tidak terlalu signifika. Namun yang terjadi pada tahun 2010 sampai dengan tahun 2013 ekspor tembakau Indonesia kembali meningkat dengan rata-rata tumbuh sebesar $12 \%$. Peningkatan nilai ekspor ini disebabkan oleh banyaknya permintaan akan rokok di luar negeri. Pada tahun 2014 sampai dengan tahun 2015 ekspor tembakau mengalami penurunan salah satu pemicu penurunan ekspor tembakau yaitu melambatnya perdagangan dunia.

\section{Hasil Penelitian Statistik Deskriptif}

\section{Tabel 1}

Statistik Deskriptif

\begin{tabular}{|l|c|c|c|}
\hline Variabel & KURS & LNJUB & LNEKSPOR \\
\hline Mean & 6982.581 & 11.86279 & 4.917277 \\
\hline
\end{tabular}

\begin{tabular}{|l|c|c|c|}
\hline Median & 8940.000 & 12.08803 & 4.852194 \\
\hline Maximum & 13795.00 & 14.02872 & 6.490605 \\
\hline Minimum & 1652.000 & 9.365376 & 3.063952 \\
\hline Std. Dev. & 4133.606 & 1.468172 & 0.974784 \\
\hline
\end{tabular}

Sumber: Hasil Pengolahan Data, 2019

Pada Tabel 1 nilai variabel KURS mempunyai, nilai rata-rata (mean) sebanyak 6982,581 dan standar deviasi dari variabel KURS sebesar 4133,606.Hal ini berarti bahwa nilai mean>standar deviasi, sehingga mengindikasikan bahwa hasil yang sangat baik.Karena standar deviasi merupakan mencerminkan penyimpangan yang sangat tinggi, sehingga penyebaran data menunjukkan hasil yang normal dan tidak menyebabkan bias.Nilai minimumnya sebesar 1.652 .000 dan nilai maksimumnya sebesar 13795.00 .

\section{Hasil Pengolahan Data Regresi Linear Berganda}

\section{Tabel 5}

Hasil Pengolahan Data Regresi Linier Berganda

\begin{tabular}{|c|c|c|c|c|c|}
\hline Variable & Coefficient & Std. Error & t-Statistic & $\mathrm{t}$-Tabel & Prob. \\
\hline C & -31324.58 & 2353.403 & -13.31034 & 2,04 & 0.0000 \\
\hline LNJUB & 4357.307 & 431.5432 & 10.09703 & 2,04 & 0.0000 \\
\hline LNEKSPOR & -2721.555 & 649.9694 & -4.187205 & 2,04 & 0.0003 \\
\hline R-squared & 0.929691 & & & & \\
\hline Adjusted R-squared & 0.924669 & & & & \\
\hline F-statistic & 185.1218 & \multirow{2}{*}{\multicolumn{2}{|c|}{$\begin{array}{l}\text { Durbin-Watson stat } \\
\text { C. Tahal }\end{array}$}} & \multirow{2}{*}{$\begin{array}{l}1.244953 \\
221\end{array}$} & \\
\hline Drah/[-etatictin) & ก กกกกกก & & & & \\
\hline
\end{tabular}

Sumber: Hasil Pengolahan Data, 2019

$$
Y_{t}=\beta_{0}+b_{1} \operatorname{Ln} X_{1} \mathrm{t}+b_{2} \operatorname{Ln} X_{2} \mathrm{t}+\mathrm{e}
$$

Berdasarkan hasil estimasi Tabel 4.5 diatas maka dapat diformulasikan sebagai berikut:

KURSt $=-31324,58+4357,30 \mathrm{LNJUBt}-$ 2721,55LNEKSPORt berikut:

Adapun interprestasi persamaanya sebagai

1. Konstanta $\left(\beta_{0}\right)=-31324,58$

Apabila variabel jumlah uang beredar dan ekspor tembakau bernilai konstan (0), maka kurs juga akan konstan sebesar - 31324, 58 rupiah.

2. Koefisien Regresi LNJUB $\left(\beta_{1}\right)=4357,30$ Apabila jumlah uang beredar meningkat sebesar Rp. 1 Milyar, maka akan terjadi peningkatan variabel kurssebesar Rp. 4357,30.

3. Koefisien Regresi LNEKSPOR $\left(\beta_{2}\right)=$ 2721,55 
Apabila variabel ekspor tembakau meningkat sebesar 1 Milyar US \$, maka mengakibatkan kurs menguat sebesar Rp. 2721,55.

\section{Hasil Uji Normalitas}

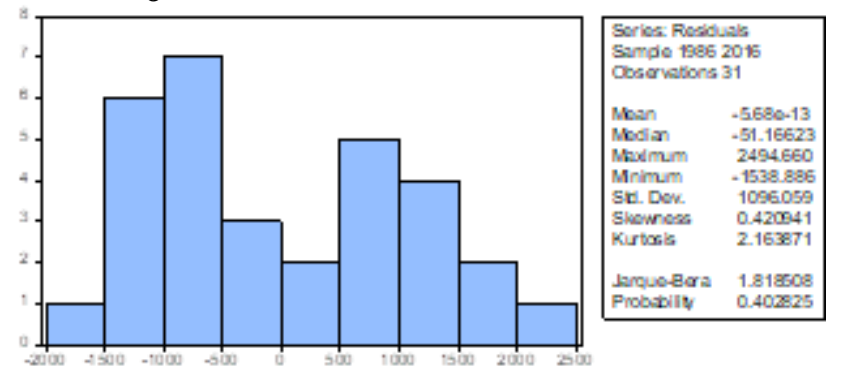

Sumber: Hasil Pengolahan Data, 2019.

\section{Gambar 8}

Uji Normalitas

Dari gambar diatas dapat disimpulkan bahwa hasil pengujia normalitas ini berdistribusi normal, terlihat pada nilai Probability 0,40 lebih besar dari taraf kepercayaan 0,01 artinya data berdistribusi normal.

\section{Uji Asumsi Klasik}

Uji Asumsi Klasik dalam penelitian ini trdiri dari:

\section{Uji Multikolineritas}

\section{Tabel 2}

Uji Multikolineritas

\begin{tabular}{|c|c|c|c|}
\hline Varaibel & $\begin{array}{c}\text { R- } \\
\text { Squared }\end{array}$ & VIF & Tolerance \\
\hline JUB & 0.893117 & 9.35602481 & 0.106883 \\
\hline $\begin{array}{c}\text { Ekspor } \\
\text { Tembakau }\end{array}$ & 0.893117 & 9.35602481 & 0.106883 \\
\hline
\end{tabular}

Sumber: Hasil Pengolahan Data, 2019.

Berdasarkan hasil diatas nilai VIF seluruh variabel berada dibawah atau lebih kecil dari 10 yang berarti bahwa data terbebas dari multikolineritas. Begitu juga nilai tolerance mendekati satu yang berarti terhindar dari multikolineritas.

\section{Uji Autokorelasi}

Tabel 3

Uji Autokorelasi Metode LM Test

Breusch-Godfrey Serial Correlation LM Test:

\begin{tabular}{|c|c|c|}
\hline F-statistic & 2.700215Prob. $\mathrm{F}(3,25)$ & 0.0672 \\
\hline $\begin{array}{l}\text { Obs*R- } \\
\text { squared }\end{array}$ & 7.586559 $\begin{array}{l}\text { Prob. Chi- } \\
\text { Square(3) }\end{array}$ & 0.0554 \\
\hline
\end{tabular}

Sumber: Hasil Pengolahan Data, 2019.
Berdasarkan tabel di atas dapat dijelaskan bahwa nilai dengan nilai Obs*R-squared $<$ df : X2 yaitu sebesar 7,586 $<9,210$ yang berarti bahwa model ini sudah terbebas dari indikasi Autokorelasi. Hal ini juga bias dilihat dari nilai Prob Chi-Square sebesar 0,0554 lebih besar dari taraf kepercayaan 0,01 .

\section{Uji Heteroskedastisitas}

Tabel 4

Uji Heteroskedastisitas

Heteroskedasticity Test: White

\begin{tabular}{llll}
\hline \hline F-statistic & 0.746133 & Prob. F(2,28) & 0.4834 \\
Obs*R-squared & 1.568555 & Prob. Chi-Square(2) & 0.4564 \\
Scaled explained SS & 0.744676 & Prob. Chi-Square(2) & 0.6891 \\
\hline \hline
\end{tabular}

Sumber: Hasil Pengolahan Data, 2019

Berdasarkan hasil uji WhiteTestmenggunakan program Eviews 9, dapat dilihat bahwa nilai $O b s^{*} R$-squared $<\mathrm{df}: X^{2}$ maka tidak ada indikasi Heteroskedastisitas. Berdasarkan hasil pengujian dari dfChi-Square pada $\alpha=1 \%$ adalah 9,210. Hasil dari $O b s^{*} R$-squared adalah 1,568< 9,210 yang berarti bahwa model ini terbebasa dari indikasi heteroskedastisitas. Hal ini dapat dilihat juga dengan Prob Chi Square sebesar 0,45 lebih besar dari 0,01 sehingga tidak terjadi heteroskedastisitas.

\section{Pengujian Hipotesis}

Pengujian hipotesis dalam penelitian ini yaitu sebagai berikut:

\section{Uji Statistik $\mathbf{t}$}

Konstanta $\left(\beta \_0\right)=-13.31$, oleh karena thitung $>\mathrm{t}$ tabel atau $-13.31>2,76$, maka tolak $\mathrm{H} 0$ dan terima Ha yang berarti bahwa variabel LNJUB dan LNEKSPOR berpengaruh secara signifikan dan negatif terhadap kurs. Hal ini juga dapat dilihat dari probabilitas (P-Value) sebesar 0,0000<0,01.

Parameter $\beta 1$ LNJUB $=10.09$ oleh karena itu nilai t_hitung $>\mathrm{t}$ tabel atau $10.09>2,76$ tolak $\mathrm{H} 0$ dan terima $\mathrm{H} 1$ yang berarti LNJUB berpengaruh secara signifikan dan positif terhadap kurs di Indonesia. Hal ini juga bisa di lihat dari probabilitas (P-value) sebesar $0,0000<0,01$.

Parameter $\beta 2$ LNEKSPOR $=-4,18$ oleh karena itu nilai $\mathrm{t}$ hitung $>\mathrm{t}$ tabel atau 4,18> 2,76 maka tolak $\mathrm{H} 0$ dan terima $\mathrm{H} 2$ yang berarti LNEKSPOR berpengaruh secara signifikan dan negatif terhadap kurs di Indonesia. Hal ini juga bisa di lihat dari probabilitas (P-value) sebesar $0.0003<$ 0,01 .

\section{Uji Statistik F}

Berdasarkan hasil Tabel 4.5 F- tabel sebesar : 185,12 oleh karena $\mathrm{f}$ hitung $>\mathrm{f}$ tabel atau 185,12 
$>$ 5,45, maka tolak H0 dan terima Ha, jadi secara bersama-sama variabel LNJUB dan LNEKSPOR berpengaruh secara signifikan dan positif terhadap KURS hal ini juga bisa di lihat dari probabilitas (P-Value) sebesar $0,0000<0,01$.

\section{Koefisien Determinasi $\left(\mathbf{R}^{2}\right)$}

Dari hasil pengolahan data diperoleh Adjusted R.Squared sebesar 0,9247 jadi besarnya pengaruh jumlah uang beredar dan ekspor tembakau terhadap kurs di Indonesia adalah sebesar 0,9247 (92,47\%), sedangkan yang dipengaruhi oleh variabel lain diluar model ini adalah sebesar $0,0753(7,53 \%)$.

\section{Koefisien Korelasi (R)}

Berdasarkan hasil pengolahan data pada tabel 4.5 diperoleh nilai korelasi $(\mathrm{R}) \sqrt{ }\left(\mathrm{R}^{\wedge} 2\right)=$ $\sqrt{ }(0,9297)=0,9642$. Jadi hubungan variabel jumlah uang beredar dan ekspor tembakau terhadap kurs di Indonesia berhubungan sangat erat atau sangat kuat secara positif, karena nilai korelasi sebesar 0,9642 mendekati positif satu $(+1)$.

\section{Vactor Autogeression (VAR)}

\section{Uji Stasioneritas}

Tabel 6

Uji Unit Root Test dengan Augmented Dickey Fuller (ADF)

\begin{tabular}{|c|l|c|c|c|l}
\hline Variabel & Unit Root & $\begin{array}{c}\text { ADF test } \\
\text { Satistic }\end{array}$ & $\begin{array}{c}\text { Critical } \\
\text { Value 5\% }\end{array}$ & Prob ADF & Keterangan \\
\hline \multirow{3}{*}{ Kurs } & Level & -2.169506 & -3.568379 & 0.4884 & Tidak \\
\cline { 2 - 6 } & First Diff & -5.178725 & -3.574244 & 0.0013 & Stasioner \\
\cline { 2 - 6 } & Second Diff & -6.780494 & -3.587527 & 0.0000 & Stasioner \\
\hline \multirow{3}{*}{ JUB } & Level & 3.501286 & -3.595026 & 1.0000 & Tidak \\
\cline { 2 - 6 } & First Diff & -4.227196 & -3.580623 & 0.0124 & Stasioner \\
\cline { 2 - 6 } & Second Diff & -7.125208 & -3.603202 & 0.0000 & Stasioner \\
\hline \multirow{3}{*}{ Ekspor } & Level & -2.743979 & -3.574244 & 0.2278 & Tidak \\
\cline { 2 - 6 } & First Diff & -2.823285 & -3.574244 & 0.2008 & Tidak \\
\cline { 2 - 6 } & Second Diff & -6.500477 & -3.580623 & 0.0001 & Stasioner \\
\hline
\end{tabular}

Sumber: Hasil Pengolahan Data, 2019.

Berdasarkan Tabel 4.6 dapat disimpulkan bahwa variabel kurs pada tingkat levelmemiliki nilai ADF < nilai kritis $1 \%$ yaitu $2.169506<-$ 3.568379 artinya data tidak stasioner pada tingkat level.Sedangkan pada tingkat First Different dengan nilai $\mathrm{ADF}>$ nilai kritis $1 \%$ yaitu 5.178725>-3.574244 artinya data stasioner pada tingkat First Different. Variabel kurs memiliki nilai ADF < nilai kritis $1 \%$ yaitu 3.501286<3.595026 artinya data tidak stasioner pada tingkat level sedangkan pada tingkat First Different nilai ADF > nilai kritis $1 \%$ yaitu -4.227196>3.580623. Variabel ekspor memiliki nilai ADF > nilai kritis $1 \%$ yaitu $-6.500477>-3.580623$ artinya ekspor stasioner pada tigkat Second Different.

\section{Penentuan Lag Optimum}

Tabel 7

Hasil Pengujian Lag Optimal

\begin{tabular}{ccccccc}
\hline \hline Lag & LogL & LR & FPE & AIC & SC & HQ \\
\hline \hline & & & & & & \\
\hline 0 & -848.6007 & NA & $6.44 e+21$ & 58.73108 & 58.87253 & 58.77538 \\
1 & -731.9040 & 201.2011 & $3.85 e+18$ & 51.30373 & 51.86950 & 51.48092 \\
2 & -712.8093 & $28.97133^{*}$ & $1.97 e+18^{*}$ & $50.60754^{*}$ & $51.59765^{*}$ & $50.91763^{*}$ \\
\hline
\end{tabular}

Sumber: Hasil Pengolahan Data, 2019.

Berdasarkan Tabel 4.7 setelah diakumulasikan maka jumlah bintang terbanyak terletak pada lag 2. Adapun maksud dari lag optimum pada penelitian ini ialah bahwa semua variabel penelitian yang digunakan dalam persamaan saling mempengaruhi satu sama lain sampai dua periode sebelumnya. Artinya bahwa variabel jumlah uang beredar dan ekspor tembakau mempengaruhi variabel kurs.

\section{Granger Causality}

Tabel 8

Hasil Uji Granger Causality

\begin{tabular}{lccc}
\hline \hline Null Hypothesis: & Obs & F-Statistic & Prob. \\
\hline \hline DDJUB does not Granger Cause DDKURS & 27 & 3.29050 & 0.0562 \\
DDKURS does not Granger Cause DDJUB & & 2.03722 & 0.1543 \\
\hline \hline DDEKSPOR does not Granger Cause DDKURS & 27 & 1.82526 & 0.1848 \\
DDKURS does not Granger Cause DDEKSPOR & & 2.17606 & 0.1373 \\
\hline \hline DDEKSPOR does not Granger Cause DDJUB & \multirow{2}{*}{27} & 1.31043 & 0.2899 \\
DDJUB does not Granger Cause DDEKSPOR & & 14.2790 & 0.0001 \\
\hline \hline
\end{tabular}

Sumber: Hasil Pengolahan Data, 2019.

Dari Tabel 8 dapat kita lihat bahwa variabel jub tidak memiliki hubungan terhadap variabel kurs.Akan tetapi variabel kurs tidak memiliki hubungan terhadap varaibel jub hal ini dapat dilihat apabila hubungan kausalitas dikatakan terjadi pada tiap-tiap varibel memiliki hubungan 2 arah yaitu signifikan pada level $1 \%$ (probability < 0.01).Variabel ekspor tidak memiliki hubungan dengan kurs, dan sebaliknya kurs tidak memiliki hubungan kausalitas terhadap ekspor karena nilai probabilitasnya $>\alpha=1 \%$. Sedangkan pada variabel ekspor terhadap jub tidak terdapat hubungan timbal balik atau 2 arah, variabel jub memiliki hubungan searah dengan ekspor dengan membandingkan nilai probabilitas $<\alpha=1 \%$. Hubungan kausalitas dikatakan terjadi apabila pada tiap-tiap varibel memiliki hubungan 2 arah yaitu signifikan pada level $1 \%$ (probability < 0.01 ). 
4. Hasil Estimasi Vector Autoregression (VAR)

\section{Tabel 9}

Uji Vector Autoregression (VAR)

\begin{tabular}{cccc} 
& DDKURS & DDJUB & DDEKSPOR \\
\hline \hline DDKURS(-1) & 0.865023 & -4.620988 & -0.005831 \\
& $(0.19372)$ & $(4.98395)$ & $(0.00610)$ \\
& {$[4.46538]$} & {$[-0.92717]$} & {$[-0.95542]$} \\
DDKURS(-2) & 0.168045 & 6.617016 & -0.001303 \\
& $(0.22267)$ & $(5.72890)$ & $(0.00701)$ \\
& {$[0.75467]$} & {$[1.15502]$} & {$[-0.18570]$} \\
DDJUB(-1) & 0.015753 & 1.228252 & 0.001594 \\
& $(0.01026)$ & $(0.26388)$ & $(0.00032)$ \\
& {$[1.53585]$} & {$[4.65455]$} & {$[4.93248]$} \\
DDJUB(-2) & -0.029837 & -0.117446 & -0.001195 \\
& $(0.01143)$ & $(0.29415)$ & $(0.00036)$ \\
& {$[-2.60976]$} & {$[-0.39928]$} & {$[-3.31891]$} \\
DDEKSPOR(-1) & 12.76293 & -39.38425 & 0.372831 \\
& $(7.19519)$ & $(185.117)$ & $(0.22667)$ \\
& {$[1.77381]$} & {$[-0.21275]$} & {$[1.64481]$} \\
DDEKSPOR(-2) & 4.771032 & -35.97342 & -0.032737 \\
& $(6.36274)$ & $(163.700)$ & $(0.20045)$ \\
& {$[0.74984]$} & {$[-0.21975]$} & {$[-0.16332]$} \\
\hline \hline
\end{tabular}

Sumber: Hasil Pengolahan, 2019.

Berdasarkan tabel 9 diatasdengan t-tabel 2,76326 maka variabel kurs berpengaruh positif dan signifikan terhadap dirinya sendiri hal ini dapat dilihat dengan nilai t hitung lebih besar dari t tabel yaitu sebesar 4,46538>2,76326. Variabel jub berpengaruh negatif dan signifikan terhadap kurs dengan nilai -2.60976> 2,04840. Ekspor berpengaruh positif dan tidak signifikan terhadap kurs karena nilai $t$ satistik lebih kecil dari nilai $t$ table yaitu sebesar $1.77381<2,76326$.

\section{Uji Stabilitas Vector Autoregression}

Tabel 10

Uji Stabilitas Vector Autoregression

\begin{tabular}{|c|l|}
\hline Root & Modulus \\
\hline 1.050703 & 1.050703 \\
\hline 0.994140 & 0.994140 \\
\hline $0.444368-0.477493 \mathrm{i}$ & 0.652275 \\
\hline $0.444368+0.477493 \mathrm{i}$ & 0.652275 \\
\hline$-0.233736-0.253818 \mathrm{i}$ & 0.345045 \\
\hline$-0.233736+0.253818 \mathrm{i}$ & 0.345045 \\
\hline
\end{tabular}

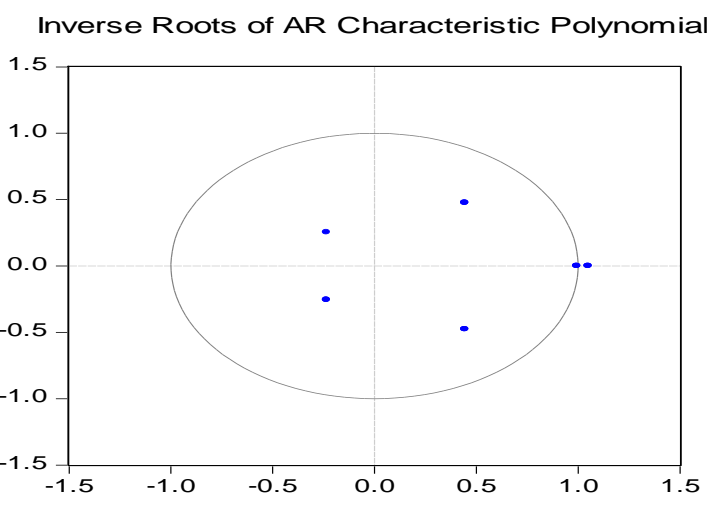

Sumber: Hasil Pengolahan Data, 2019.

Keterangan :Pengujian stabilitas VAR dengan AR Roots Table dan Ar Roots Graph

Berdasarkan hasil pengujian stabilitas

Vector Autoregression pada tabel 10 menunjukkan bahwa persamaan VAR memiliki nilai modulus kurang dari satu pada lag 2 sehingga dapat disimpulkan bahwa model VAR yang dibentuk tidak stabil karena nilai modulus lebih besar dari 1. Vector Autoregression (VAR) dikatakan stabil apabila seluruh nilai dari Root Characteristik memiliki modulus lebih kecil dari 1.Pada Graph dapat dilihat bahwa titik invers roots of AR polynominal hanya satu yang berada di luar lingkaran. Hal ini mengindikasikan bahwa VAR tidak stabil.

\section{Implus Response}
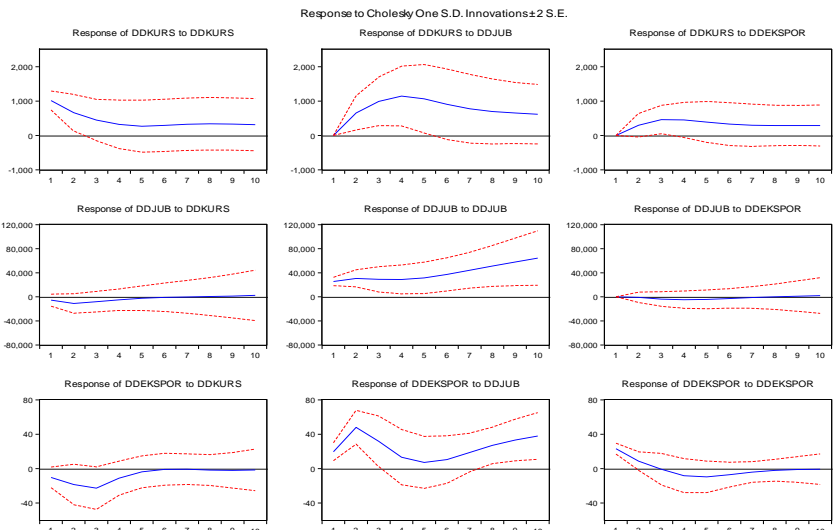

Sumber: Hasil Pengolahan Data, 2019.

\section{Gambar 6 Implus Respon}

Pada Gambar 6 terlihat bahwapada tahun pertama nilai tukar mengalami depresiasi dan pada tahun ke dua terjadi guncangan terhadap variabel itu sendiri sehingga nilai tukar menguat dan sampai pada tahun keempat nilai tukar kembali stabil. Sedangkan variabel jumlah uang beredar dari tahun pertama sampai tahun keempat menurun signifikan dan negatif serta tahun kelima mencapai titik kesimbangan atau equilibriumnya.Artinya butuh waktu empat tahun agar kurs mengalami kestabilan setelah terjadi shock pada JUB.

Respon ekspor terhadap kurs pada awal periode mengalami fluktuasi negatif sampai tahun keenam dan mencapai titik keseimbangan pada tahun ketujuh.Kemudian respon ekspor mengalami fluktuasi dari tahun pertama mengalami peningkatan dan menurun pada tahun ketiga serta negatif dari tahun keempat sampai tahun ke delapan terhadap variabel itu sendiri.Artinya butuh waktu enam tahun agar ekspor agar kembali stabil. 


\section{Analisis Variance Decomposition}

Tabel 11

Varian Decompositiokurs

\begin{tabular}{rcccc} 
Period & S.E. & DDKURS & DDJUB & DDEKSPOR \\
\hline \hline 1 & 1016.591 & 100.0000 & 0.000000 & 0.000000 \\
2 & 1408.580 & 74.11913 & 21.48382 & 4.397050 \\
3 & 1838.401 & 49.42669 & 41.68534 & 8.887964 \\
4 & 2234.828 & 35.49399 & 54.42587 & 10.08014 \\
5 & 2520.320 & 29.03686 & 60.64294 & 10.32020 \\
6 & 2714.008 & 26.20077 & 63.43722 & 10.36201 \\
7 & 2856.355 & 24.94144 & 64.63622 & 10.42234 \\
8 & 2973.096 & 24.30702 & 65.13726 & 10.55572 \\
9 & 3075.254 & 23.87204 & 65.37544 & 10.75252 \\
10 & 3165.081 & 23.51091 & 65.50304 & 10.98605 \\
\hline \hline
\end{tabular}

Sumber:Hasil Pengolahan Data,

Berdasarkan hasil analisis Variance Decomposition kurs pada Tabel 11 dapat dilihat pada awalnya kurs masih sangat dipengaruhi oleh kurs itu sendiri yakni sebesar $100 \%$ dimana jub dan ekspor belum memberikan pengaruh sama sekali. Namun pada tahun-tahun selanjutnya kontibusi shock jub dan ekspor mengalami kenaikan hingga tahun ke 10 jub 65,50 persen dan ekspor sebesar 10,98 persen. Hal ini mengikuti penurunan proporsi shock kurs terhadap variabel kurs itu sendiri namun sampai tahun ke 10 kontribusinya masih relative besar yakni 23.51 persen.

\section{Pembahasan}

Hubungan Jumlah Uang Beredar Terhadap Kurs mengunakan model Regrsi Linear Berganda dan Vector Autoregression

1. Hasil pengujian yang telah dilakukan menggunakan Regresi Linear Berganda dapat dilihat bahwa jumlah uang beredar berpengaruh secara positif dan signifikan terhadap kurs hal ini sesuai dengan penelitian saudariMuchlas, (2015).

2. Hasil pengujian yang telah dilakukan menggunakan modl VAR dapat disimpulkan bahwa jumlah uang beredar memilki hubungan positif dan tidak signifikan terhadap kurs. Hal ini sesuai dengan pendapat Ardiyanto \& Ma'aruf, (2014),Murtala et al ., (2019),.Murtala, (2017)dan (Demak, Kumaat, \& Mandeij (2018).

\section{Hubungan Ekspor TembakauTerhadap Kurs}

1. Berdasarkan hasil pengujian yang telah dilakukan dapat dilihat bahwa ekspor tembakau berpengaruh secara negatif dan signifikan terhadap kurs. Artinya semakin besar ekspor tembakau, maka semakin menguat kurs terhadap dollar di Indonesia. Penelitian ini didukung pula oleh penelitian yang dilakukan oleh saudari Dzakiyah et al ., (2018), menurut penelitian ekspor neto berpengaruh positif dan signifikan terhadap nilai tukar rupiah per US dolar.

2. Berdasarkan hasil pengujian yang telah dilakukan menggunakan model VAR dapat disimpulkan bahwa ekspor tembakau berpengaruh positif dan tidak signifikan terhadap nilai tukar. Hal ini sesuai dengan pendapat Sanusi (2004), yang mengatakan bahwa apabila ekspor meningkat maka nilai tukar juga akan menguat terhadap dollar begiru pula sebalikya apabila suatu negara rendah nilai ekspornya maka nilai tukar juga akan terdepresiasi.Penelitian ini didukung pula oleh penelitian yang dilakukan oleh saudari Sabtiadi \& Kartikasari (2018)dengan hasil penelitian bahwa ekspor nasional memiliki pengaruh terhadap nilai tukar USD dan SGD. Sedangkan menurut Dzakiyah, Puspitaningtyas, \& Puspita (2018), hasil penelitian bahwa nilai ekspor tidak berpengaruh signifikan terhadap nilai tukar rupiah

\section{KESIMPULAN DAN SARAN}

\section{Kesimpulan}

Berdasarkan hasil penelitian yang dilakukan dengan menggunkaan dua alat analisa yaitu model regresi linear berganda dan model VAR, sebagai berikut ini:

1. Secara parsial jumlah uang beredar berpengaruh secara signiifikan dan positif terhadap kurs dan ekspor berpengaruh secara signifikan dan negative terhadap kurs sedangkan secara simultan jumlah uang beredar dan ekspor berpengaruh secara signifikan dan positif terhadap kurs.

2. Berdasarkan modal VAR Variabel kurs berpengaruh positif dan signifikan terhadap dirinya sendiri. Variabel jub berpengaruh positif dan tidak signifikan terhadap kurs. Ekspor berpengaruh positif dan signifikan terhadap kurs. 
Saran

Berdasarkan hasil pengolahan data dan dengan keterbatasan terdapat beberapa saran yang dapat diberikan, yaitu:

1. Perlu adanya disiplin yang ketat dalam mengendalikan jumlah uang beredar dan ekspor oleh bank indonesia sebagai otoritas moneter di Indonesia, karena faktor ini ternyata memiliki pengaruh yang signifikan pada perubahan nilai tukar. Sehingga diharapkan tingkat nilai tukar rupiah terhadap dollar Amerika dapat dicapai sesuai target yang diharapkan.

2. Pemerintah harus mengurangi penambahan jumlah uang beredar dan hasrat untuk mencetak uang agar nilai tukar mengaut terhadap dollar / stabil.

3. Untuk meningkatkan daya saing ekspor tembakau Indonesia di pasar dunia, diperlukan peran pemerintah dan pelaku ekspor agar produksi ekspor tembakau Indonesia mampu bersaing dengan negara lain.

\section{DAFTAR PUSTAKA}

Abimanyu, Y. (2004). Memahami Kurs Valuta Asing. Jakarta: Lembaga Penerbit Fakultas Ekonomi Universitas Indonesia.

Ardiyanto, F., \& Ma'ruf, A. (2014). Pergerakan Nilai Tukar Rupiah Terhadap Dollar Amerika Dalam Dua Periode Penerapan Sistem Nilai Tukar, 15(2).

Arikunto, S. (2010). Prosedur Penelitian: Suatu Pendekatan Praktik. Edisi Revisi. In Jakarta: PT.Rineka Cipta.

Atlas Tembakau Indonesia. (2013). Jakarta Selatan: Tobacco Control Support CenterIkatan Ahli Kesehatan Masyarakat Indonesia.

Bau, A. F., Kumaat, R. J., \& Niode, A. O. (2016). FAktor-Faktor yang Mempengaruhi Fluktuasi Nilai Tukar Rupiah Terhadap Dolar Amerika Serikat. Jurnal Berkala Ilmiah Efesiensi, 16(3), 524-535.

Boediono. (2000). Ekonomi Mikro. Yogyakarta: BPFE UGM.

Demak, U. D. . K., Kumaat, R. J., \& Mandeij, D. (2018). (EFFECT OF MONEY SUPPLY AND INFLATION ON THE RUPIAH AGAINST THE DOLLAR). Jurnal Berkala
Ilmiah Efisiensi, 18(2), 181-192.

Firdaus, M. (2004). Ekonometrika Suatu Pendekatan Aplikatif. Jakarta: Bumi Aksara.

Ghozali, I. (2012). Aplikasi Analisis Multivariate dengan Program IBM SPSS. Yogyakarta: Universitas Diponegoro.

Gujarati, D. N. (2003). Ekonometri Dasar (Terjemahan). Jakarta: Erlangga.

Gujarati, D. N. (2006). Dasar-Dasar Ekonometrika. Edisi Ketiga. In Jakarta: Erlangga.

Keown, A. J. (2005). Manajemen Keuangan: Prinsip dan Penerapan (Kesepuluh,). Jakarta Pusat: Indeks.

Landa, T. N. (2017). Pengaruh Jumlah Uang Beredar dan Suku Bunga BI Terhadap Kurs Rupiah di Indonesia Periode 2005-2014. JOM Fekon, 4(1).

Mankiw, N. G. (2007). Makro Ekonomi (6th ed.). Jakarta: Erlangga.

Masta, S. (2014). Analisis Vector Autoregresion (Var) Terhadap Interrelationship Antara Ipm Dan Pertumbuhan.

Mohamad, K. (2013). Atlas Tembakau Indonnesia. Jakarta: Tobacco Control Support CenterIkatan Ahli Kesehatan Masyarakat Indonesia.

Muchlas, Z., \& Alamsyah, A. R. (2015). FaktorFaktor Yang Mempengaruhi Kurs Rupiah Terhadap Dolar Amerika Pasca Krisis (20002010). Jurnal JIBEKA, 9(1), 76-86.

Murtala, Raja M., Fajri, \& Muhammad,N, (2017). Fluctuation Analysis Of Rupiah Exchange Rate Of Dollar United States In Indonesia. European Journal of Agriculture and Forestry Research. Vol.5, No.6, Pp.37-50, June 2017

Murtala, Chalirafi, Teuku R.I.P., Eddy G., irham. (2019). Rupiah exchange rate stabiliti towards US dollar in Indonesia by VAR Approach. Internasional journal of academic research in business \& social sciences. Vol 9 No \$, 2019: 174-191

Noor, Z. Z. (2011). Pengaruh Inflasi, Suku Bunga, dan Jumlah Uang Beredar terhadap Nilai Tukar, 10(2), 139-147.

Nopirin. (2017). Ekonomi Internasional. Ekonomi Internasional (Ketiga). Yogyakarta: BPFEYOGYAKARTA.

Puspita, C. A. (2017). Analisis Vector Error Correction Model (VECM) Terhadap Data Kurs , BI Rate dan Inflasi di Indonesia Pada Bulan Juli 2005 - JULI 2016, 2016.

Rachmat, Muchijidin, \& Nuryanti, S. (2009). Dinamika Agribisnis Tembakau Dunia dan Implikasi badi Indonesia. Forum Penelitian Agro Ekonomi, 27(2).

Sabtiadi, K., \& Kartikasari, D. (2018). Analisis 
Pengaruh Ekspor Impor Terhadap Nilai Tukar USD dan SGD. Jurnal Akuntansi, Ekonomi Dan Manajemen Bisnis, 6(2), 135141.

Serfianto, R Purnomo, D Serfiyani , Cita, Y., \& Hariyani, I. (2013). Pasar Uang \& Pasar Valas. Jakarta: PT Gramedia Pustaka Utama.

Sugiyono. (2005). Statistik Untuk Penelitian. In Bandung: CV.Alfabeta.

Sugiyono. (2013). Metode Penelitian Pendidikan Pendekatan Kuantitatif, Kualitatif, dan $R \& D$. Bandung: Alfabeta.

Sukirno, S. (2013). Makro Ekonomi Teori Pengantar. In Makro Ekonomi Teori Pengantar. Jakarta: PT. Raja Grafindo Persada.

Todaro, M. P. (2000). Pembangunan Ekonomi di Dunia Ketiga. Jakarta: Erlangga.

Widarjono, A. (2013). Ekonometrika (Keempat). Yogyakarta.

Widarjono, A. (2017). Ekonometrika Pengantar dan Aplikasinya (Edisi Keem). Yogyakarta: UUP STIM YKPN.

Widarjono, A. (2018). Ekonometrika edisi keempat. Yogyakarta: UPP STIM YKPN. 